\title{
PHARMACOKINETIC STUDY OF A NEW SEMISYNTHETIC CEPHALOSPORIN (AL-226) IN RABBITS
}

\author{
A. A. Dominguez-Gil, ${ }^{*}$ M. Cepeda, ${ }^{*}$ J. L. Vila and J. J. Garcia \\ Practical Pharmacy Department, Faculty of Pharmacy, University of Santiago de Compostela \\ Santiago de Compostela, Spain
}

(Received for publication December 20, 1978)

\begin{abstract}
The pharmacokinetics of AL-226, a new semi-synthetic cephalosporin, were studied after i.v. and i.m. administrations to rabbits at doses of $10,20,30$ and $40 \mathrm{mg} / \mathrm{kg}$. The average values of the pharmacokinetic parameters after bolus i.v. administration of the antibiotic expressed by an open two-compartment kinetic model were: $\alpha=0.131 \mathrm{~min}^{-1}$, $\beta=0.0341 \mathrm{~min}^{-1}, K_{12}=0.0287 \mathrm{~min}^{-1}, K_{21}=0.0552 \mathrm{~min}^{-1}, K_{13}=0.081 \mathrm{~min}^{-1}$

A linear relationship between $C_{0}$ and dose was found. The urinary excretion constants after i.v. administration were: $0.0266 \mathrm{~min} .^{-1}, 0.0294 \mathrm{~min}^{-1}, 0.0289 \mathrm{~min}^{-1}, 0.0306 \mathrm{~min}^{-1}$, for doses of $10,20,30$ and $40 \mathrm{mg} / \mathrm{kg}$, respectively. The pharmacokinetic parameters after i.v. administration were used to determine the absorption constant: $0.0525 \mathrm{~min}^{-1}, 0.057 \mathrm{~min}^{-1}$, $0.0596 \mathrm{~min}^{-1}, 0.0511 \mathrm{~min}^{-1}$, after i.m. administration for doses of $10,20,30$ and $40 \mathrm{mg} / \mathrm{kg}$, respectively.
\end{abstract}

AL-226, the potassium salt of 7-[D-( $\alpha$-hydroxy- $\alpha$-phenylacetamide)]-3-methyl-3-cephem - carboxylic acid, is a new semi-synthetic cephalosporin derived from 7-amino-deacetoxycephalosporanic acid; its structure is shown in Fig. 1. This antibiotic has an wide spectrum of activity; and is effective against Staphylococcus aureus, penicillin-sensitive and penicillin-resistant organisms, Streptococcus sp. (Viridans group), Streptococcus pyogenes (Group A), Bacillus subtilis, B. aureus at MIC's lower than $32 \mu \mathrm{g} / \mathrm{ml}$, the organisms Escherichia coli $(93 \%)$, Proteus sp. $(67 \%)$, Klebsiella pneumoniae $(40 \%)$ are inhibited. It is also active against Providencia, Enterobacter, and Pseudomonas aeruginosa. The degree of plasma protein binding was $38.5 \%$ and $36.0 \%$ in humans and rabbits, respectively, as determined by ultrafiltration (This antimicrobial data was presented by Lafarquim-Alonga at the VI National Congress of Microbiology, 6 9 July Fig. 1. Structure of AL-226.

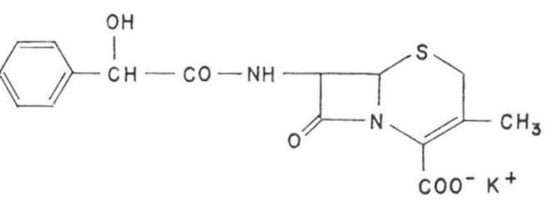
1977 at the University of Santiago de Compostela, Spain.)

The principal aim of this paper is to establish the pharmacokinetic parameters of AL-226 as a function of the dose after intravenous and intramuscular administrations.

\section{Materials and Methods}

Antibiotic

AL-226 (Lafarquim, Spain patent 438895, 1975) was synthesized by the Alonga \& Lafarquim Laboratories, Spain.

Animals

The rabbits used in this study were New Zealand white adult males weighing $1.5 \sim 2.5 \mathrm{~kg}$.

* Present Address: Practical Pharmacy Department, Faculty of Pharmacy, University of Salamanca, Salamanca, Spain. 
Bolus intravenous administration

The animals used underwent cannulation of the carotid artery following anesthesia with an intravenous dose of $30 \mathrm{mg} / \mathrm{kg}$ body weight sodium pentobarbital ${ }^{1)}$. Once the animals had recovered and were awake, AL-226 in the form of its potassium salt, dissolved in $0.5 \mathrm{ml}$ of sterile distilled water was administered in doses of $10,20,30$ and $40 \mathrm{mg} / \mathrm{kg}$ to a total of 28 rabbits ( 7 different ones for each dose) through the marginal ear vein. Heparinized blood samples were withdrawn at 0 (immediately before administration of the antibiotic), 3, 5, 10, 15, 20, 25, 30, 45, 60, 90 and 120 minutes after administration of the drug. Plasma was separated by centrifugation and was used to assay antimicrobial activity.

The bladders of another series of rabbits (10 different animals for each dose) were emptied and following this, after administration of the antibiotic, urine samples were taken through a direct and permanently fixed catheter at intervals of $0 \sim 1,1 \sim 2,2 \sim 3,3 \sim 4$ and $4 \sim 5$ hours. Urine samples were brought to a $\mathrm{pH}$ of 7.0 by addition of SöRENSEN's phosphate buffer.

Rabbits were operated under anesthetic with sodium pentobarbital and the biliary ducts were cannulated with polyethylene tubes for collecting the bile samples still under anesthetic of another 16 animals ( 4 different rabbits for each dose) at intervals of $0 \sim 0.5,0.5 \sim 1.0,1.0 \sim 1.5,1.5 \sim 2.0,2.0 \sim 3.0$, $3.0 \sim 4.0$ hours. Bile samples were brought to a pH of 7.0 by addition of SöRENSEN's phosphate buffer.

Intramuscular administration

Another group of 24 rabbits ( 6 different ones each dose) was used, to which 10, 20, 30 and $40 \mathrm{mg} /$ $\mathrm{kg}$ body weight of the potassium salt of AL-226 dissolved in $0.5 \mathrm{ml}$ of sterile distilled water were administered intramuscularly. The animals in this series underwent the same operation as those described in intravenous administration in order to obtain heparinized blood samples at intervals of $0,3,5,7,10,12,15,20,25,30,40,50,70$, and 90 minutes after administration. Plasma separated by centrifugation was again used for the assay of antimicrobial activity.

Microbiological assay

Concentrations of the antibiotic of each sample (plasma, urine, bile) were determined by an agar disc plate method ${ }^{6)}$ using Bacillus subtilis (ATCC 6633) as the test organism. All assays were repeated a minimum of 4 times.

\section{Results}

\section{Intravenous Administration}

Fig. 2 shows the average levels of AL-226 in plasma, excreted urine and bile after intravenous injection of doses of $10,20,30$ and $40 \mathrm{mg} / \mathrm{kg}$ body weight. The pharmacokinetic analysis of the plasma concentrations show that AL-226 is distributed according to an open two-compartment kinetic model according to the interval of the doses studied ${ }^{8)}$. The biexponential equation which corresponds to the intravenous curve is the following:

$$
C_{\mathrm{AL}-226}=A_{0} \cdot e^{-\alpha t}+B_{0} \cdot e^{-\beta t}
$$

The parameters of the equation (1) for AL-226 are shown in Table 1, together with the values of the distribution constants to and from the peripheric compartment, $\left(K_{12}, K_{21}\right)$ the elimination constant of the antibiotic $\left(K_{13}\right)$, the plasma half life during the rapid and slow disposition phases $\left(\mathrm{t} \frac{1}{2} \alpha, \mathrm{t} \frac{1}{2} \beta\right)$, and also the apparent distribution volumes of the central $\left(\mathrm{V}_{\mathrm{c}}\right)$, and peripheric $\left(\mathrm{V}_{\mathrm{p}}\right)$ compartments ${ }^{7}$.

As the parameters $\alpha$ and $\beta$ were calculated from regression lines ( $\alpha$ being obtained by method of residuals and $\beta$ from the slow disposition phase of the plasma levels curve), we have made a statistical comparison of the difference between the slopes of the rapid disposition phase for the doses that were administered and also between the slopes of the slow disposition phase for the doses that were administered by means of the $t$-test ${ }^{14}$. When $\mathrm{p}=0.05$, there are no statistically significant differences 
between the slopes of the various regression lines, thus we may accept the following average values: $\alpha=0.131 \mathrm{~min}^{-1}, \beta=0.0341 \mathrm{~min}^{-1}$. From these values, the distribution and elimination constants may be calculated and are found to have the following average values: $K_{12}=0.0287$ $\pm 0.00184 \mathrm{~min}^{-1}, \quad K_{21}=0.0552 \pm 0.00468 \mathrm{~min}^{-1}$, $K_{13}=0.0810 \pm 0.00651 \mathrm{~min}^{-1}$. The plasma half lives were $t \frac{1}{2} \alpha=5.29 \mathrm{~min}$., $\mathrm{t} \frac{1}{2} \beta=20.33 \mathrm{~min}$.

The concentrations of AL-226 in the central and peripheric compartments may be calculated from the following expressions ${ }^{13)}$ :

Central compartment

$$
C=C_{0}\left(0.217 \cdot e^{-0.0341 \cdot t}+0.783 \cdot e^{-0.131 \cdot t}\right)
$$

Peripheric compartment

$$
C=C_{0} \cdot 0.5680\left(e^{-0.0341 \cdot t}-e^{-0.131 \cdot t}\right)
$$

Table 1. Parameters for the two-compartment, open-system model estimated from concentration of AL-226 in plasma after i.v. administration of four doses to rabbits.

\begin{tabular}{l|c|c|c|c}
\hline \multirow{2}{*}{$\begin{array}{c}\text { Param- } \\
\text { eter }\end{array}$} & \multicolumn{4}{|c}{ Doses in $\mathrm{mg} / \mathrm{kg}$} \\
\cline { 3 - 5 } & 10 & 20 & 30 & 40 \\
\hline$C_{0} \mu \mathrm{g} / \mathrm{ml}$ & 40.82 & 75.28 & 120.72 & 170.71 \\
$A_{0} \mu \mathrm{g} / \mathrm{ml}$ & 32.93 & 61.90 & 94.68 & 121.70 \\
$B_{0} \mu \mathrm{g} / \mathrm{ml}$ & 7.89 & 13.38 & 26.04 & 49.01 \\
$\alpha \mathrm{min} .^{-1}$ & 0.130 & 0.141 & 0.124 & 0.128 \\
$\beta \mathrm{min}^{-1}$ & 0.0309 & 0.0380 & 0.0359 & 0.0316 \\
$\mathrm{t} \frac{1}{2} \propto \mathrm{min}$. & 5.35 & 4.91 & 5.57 & 5.40 \\
$\mathrm{t} \frac{1}{2} \beta \mathrm{min}^{-}$ & 22.46 & 18.24 & 19.31 & 21.96 \\
$K_{12} \mathrm{~min} .^{-1}$ & 0.0305 & 0.0276 & 0.0241 & 0.0323 \\
$K_{21} \mathrm{~min} .^{-1}$ & 0.0499 & 0.0563 & 0.0597 & 0.0593 \\
$K_{13} \mathrm{~min} .^{-1}$ & 0.0801 & 0.0950 & 0.0812 & 0.0682 \\
$\mathrm{~V}_{\mathrm{e}} \mathrm{ml} / \mathrm{kg}$ & 244.97 & 265.67 & 248.50 & 234.31 \\
$\mathrm{~V}_{\mathrm{p}} \mathrm{ml} / \mathrm{kg}$ & 149.37 & 130.24 & 108.99 & 127.58 \\
\hline
\end{tabular}

Fig. 2. shows the average percentage values of AL-226 excreted in active form in urine after the bolus i.v. administration at 4 different doses for five hours.

Urinary excretion may be defined by (2):

$$
\log \left(U_{\max }-U_{t}\right)=-\frac{K u}{2.303} \cdot t+\log U_{\max }
$$

Fig. 2. Average values of plasma levels of AL-226 together with biliary and urinary excretion after i.v. administration of $10,20,30$ and $40 \mathrm{mg} / \mathrm{kg}$.

The standard deviation (SD) of the mean is represented by the vertical bars.
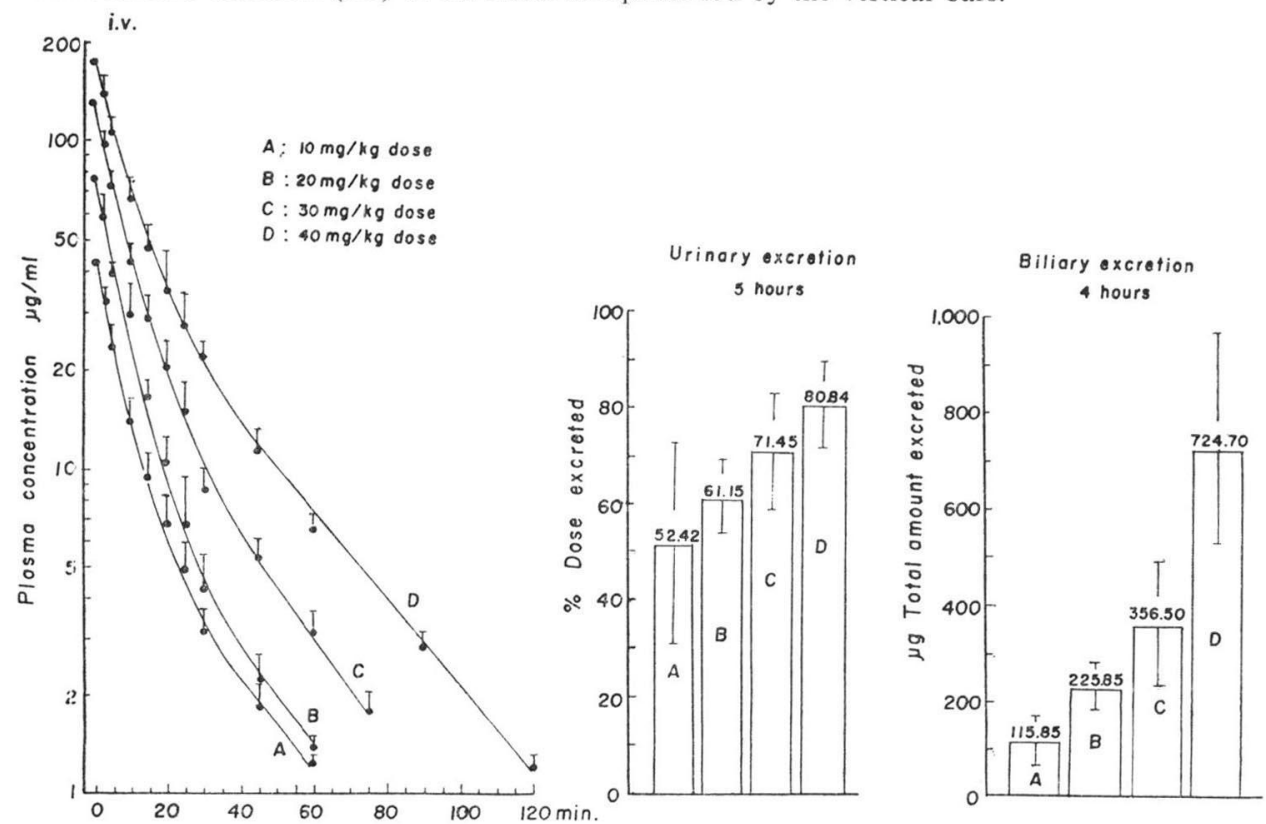
Table 2. Relationship between $\log \left(U_{\max }-U_{\mathrm{t}}\right)$ of AL-226 and the excretion time in hours. Analysis of variance of the regression and linearity. Urinary excretion constant $\left(K_{\mathrm{u}}\right)$.

\begin{tabular}{c|c|c|c|c}
\hline $\begin{array}{c}\text { Doses } \\
\mathrm{mg} / \mathrm{kg}\end{array}$ & $\begin{array}{c}\text { Straight line equation } \\
\mathrm{Y}=\mathrm{a}\left( \pm \mathrm{S}_{\mathrm{a}}\right) \mathrm{x}+\mathrm{b}\left( \pm \mathrm{S}_{\mathrm{b}}\right)\end{array}$ & $\begin{array}{c}\text { F of the } \\
\text { regression } \\
\mathrm{df}-1 \text { and 45 }\end{array}$ & $\begin{array}{c}\text { F of deviation from } \\
\text { linear regression } \\
\text { df- 3 and 45 }\end{array}$ & $\begin{array}{c}K_{\mathrm{u}} \\
\text { min. }^{-1}\end{array}$ \\
\hline 10 & $\mathrm{Y}=-0.692( \pm 0.0256) \mathrm{X}+1.637( \pm 0.0513)$ & $717^{++}$ & 0.739 N.S. & 0.0266 \\
20 & $\mathrm{Y}=-0.767( \pm 0.0291) \mathrm{X}+1.716( \pm 0.0581)$ & $675^{++}$ & 0.500 N.S. & 0.0294 \\
30 & $\mathrm{Y}=-0.752( \pm 0.0307) \mathrm{X}+1.744( \pm 0.0614)$ & $641^{++}$ & 2.06 N.S. & 0.0289 \\
40 & $\mathrm{Y}=-0.797( \pm 0.0399) \mathrm{X}+1.808( \pm 0.0677)$ & $550^{++}$ & 0.708 N.S. & 0.0306 \\
\hline
\end{tabular}

Statistically significant: N. S. not significant, $\mathrm{P}>0.05 ;{ }^{+} \mathrm{P}>0.01 ;{ }^{++} \mathrm{P}>0.001$. The significance of the regression and linearity are calculated according to ScHWARTZ ${ }^{9}$. When the deviation from linear regression is not significant, the hypothesis of linearity can be retained.

Where $U_{\max }=$ maximum percentage of the dose excreted and $U_{t}=$ percentage of dose excreted after time $t$.

There exists a relationship in the form of a linear regression between the logarithm of the percentage of the dose which is still to be excreted $\left(U_{\max }-U_{t}\right)$ and the interval of excretion of all the doses that were studied, the equations obtained being shown in Table 2.

The significance of the relation between the two variables is given by the F-test of regression and the results show that the $\mathrm{F}$-values (regression $\mathrm{F}$ is very significant and the $\mathrm{F}$ of deviation from linear regression is not significant) are acceptable for all the doses. This table also shows the values of the urinary excretion constant $\left(K_{u}\right)$ calculated from the corresponding equations.

Fig. 3. Average values of AL-226 in plasma after i.m. administration of four doses.

The solid line is the computer derived curve. Standard deviation (SD) is represented by the vertical bars.
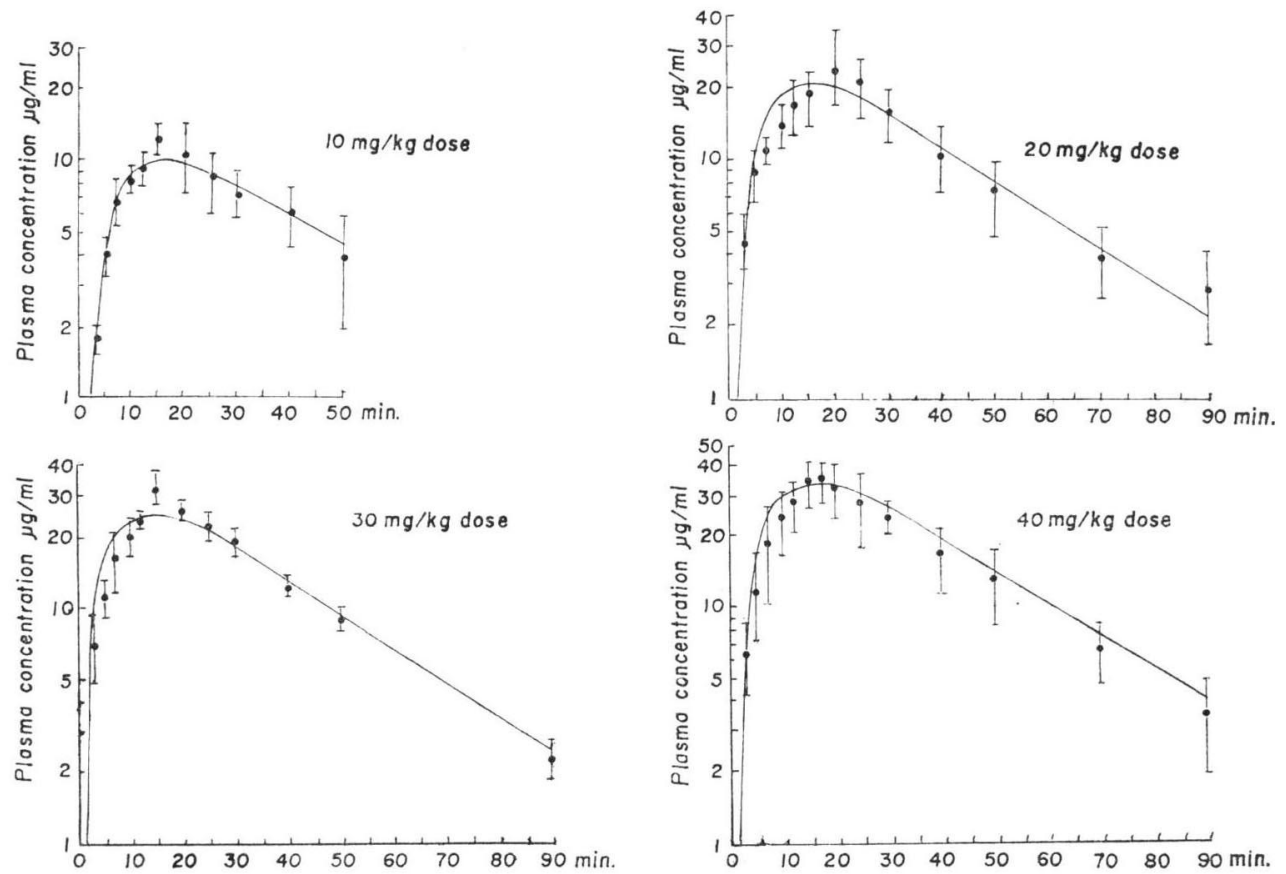
The average values of the total $\mu \mathrm{g}$ of AL-226 in active form excreted in bile after bolus i.v. administration of 4 doses are shown in Fig. 2. The total $\mu \mathrm{g}$ of AL-226 excreted after 4 hours increases according to the increase in the dose of the antibiotic administered.

Intramuscular Administration

Fig. 3 shows the average values of the experimental plasma concentrations of AL-226 in active form after the administration of doses of $10,20,30$ and $40 \mathrm{mg} / \mathrm{kg}$ body weight. The absorption constant $\left(K_{01}\right)$ was calculated by the method of LOO-RIEGELMAN ${ }^{5)}$ and gave values of $0.0525 \mathrm{~min}^{-1}$, $0.0575 \mathrm{~min}^{-1}, 0.0596 \mathrm{~min}^{-1}$ and $0.0511 \mathrm{~min}^{-1}$ for the doses of $10,20,30$ and $40 \mathrm{mg} / \mathrm{kg}$. The bioavailability ${ }^{3)}$ values were found to be $97.6 \%, 94.8 \%, 76.6 \%$ and $80 \%$ for the doses of $10,20,30$ and $40 \mathrm{mg} / \mathrm{kg}$.

The drug plasma concentration-time curves may be defined to be the following equation ${ }^{12}$ :

$$
C_{A 1-226}=f \cdot K_{01} C_{0}\left[\frac{\left(K_{21}-\alpha\right) \cdot e^{-\alpha\left(t-t^{\prime}\right)}}{\left(K_{01}-\alpha\right) \cdot(\beta-\alpha)}+\frac{\left(K_{21}-\beta\right) \cdot e^{-\beta\left(t-t^{\prime}\right)}}{\left(K_{01}-\beta\right) \cdot(\alpha-\beta)}+\frac{\left(K_{21}-K_{01}\right) e^{-K_{01}\left(t-t^{\prime}\right)}}{\left(\alpha-K_{01}\right)\left(\beta-K_{01}\right)}\right]
$$

where $f$ is the bio-availability, $t^{\prime}$ is the latency period $(2.03 \mathrm{~min}$., $2.24 \mathrm{~min}$., $1.06 \mathrm{~min}$., $2.09 \mathrm{~min}$., for $10,20,30$ and $40 \mathrm{mg} / \mathrm{kg}$ doses respectively) and the rest of the parameters are obtained from i.v. data. The theoretical curves of the plasma levels, obtained from equation 2 using a Compucorp 327 computer, are shown in Fig. 3.

\section{Discussion}

AL-226 administered by intravenous bolus injections to rabbits shows a rapid and slow disposition constant $(\alpha$ and $\beta$ ) together with the corresponding plasma half-lives which are not altered in the interval of the doses studied. The speed of distribution into the peripheric compartment is less than the speed of return to the central compartment $\left(K_{12} / K_{21}=0.52\right)$ steady state being reached in a relatively short time $\left(K_{12} / K_{13}=0.35\right)$ and being distributed in a small volume of the peripheric compartment, since $V_{c}>V_{p}$ for all doses. The retention of AL-226 in the peripheric compartment is limited due to the low value of $V_{p}$. This kinetic behaviour of AL-226 is very different from that found by YAMAZAKI et $a l .{ }^{15}$ ) for cefalexin and SCE-100 under the same experimental conditions at doses of $10 \mathrm{mg} / \mathrm{kg}$ administered intravenously where the relationship $K_{12} / K_{21}=7.52$ for the former and 4.23 for the latter, $V_{c}$ being much smaller than $V_{p}$ in both cases.

As for other drugs, we have found the following linear relationships ${ }^{10,11)}$ :

$$
C_{0}=4.12 \pm 0.102 x \quad x=\text { dose in } \mathrm{mg} / \mathrm{kg} .
$$

This relationship allows us to find the parameter for doses up to $40 \mathrm{mg} / \mathrm{kg}$ which have not been studied. The values of $C_{0}$ calculated from experimental data for cephalexin, and SCE-100 was $16.9 \mu \mathrm{g} / \mathrm{ml}$ and $16.6 \mu \mathrm{g} / \mathrm{ml}$ respectively, at a dose of $10 \mathrm{mg} / \mathrm{kg}$, that is 2.43 times lower than that found for AL-226. However, while for AL-226, after 2 hours and at greater doses, no antibiotic may be detected in plasma, appreciable concentrations of the other cephalosporins may be detected in plasma after 6 hours.

Under our constant experimental conditions, comparing with the experimental results obtained by HARADA et al. ${ }^{4)}$ it may be seen that AL-226 has an elimination phase which is very similar to that of cephalothin for doses of 10 and $20 \mathrm{mg} / \mathrm{kg}$.

The total values excreted in urine, expressed as percentage of dose for AL-226 at a dose of $10 \mathrm{mg} /$ $\mathrm{kg}$ are similar to those found by YAMAZAKI et al. ${ }^{15)}$ for cephalexin and SCE-100 after 6 hours. While at a dose of $20 \mathrm{mg} / \mathrm{kg}$ it is 1.44 times lower than that found for cefazolin and ceftezole ${ }^{4)}$ after 6 hours.

The fact that the constant of the elimination phase of i.v. administration ${ }^{(\beta)}$ is slightly greater than the apparent elimination constant $K_{\mathrm{u}}$ is explainable if we bear in mind that AL-226 is excreted in 
bile, although however, it is inferior to that obtained for cephalexin and SCE-100.

AL-226 is rapidly absorbed when administered intramuscularly as may be seen from the fact that the maximum of the plasma concentrations is reached after 15 minutes for all doses except for $20 \mathrm{mg} / \mathrm{kg}$, which is reached 20 minutes after administration of the antibiotic, after which a rapid decrease is observable for all doses. However, the antibiotic in active form was found in plasma 90 minutes after intramuscular administration at doses of 20,30 and $40 \mathrm{mg} / \mathrm{kg}$. Under our same conditions, the maximum plasma level reached for cefazolin and cephalothin was greater than that of AL-226 at a dose of $20 \mathrm{mg} / \mathrm{kg}^{4)}$.

\section{Acknowledgments}

This research was supported by Laboratories Lafarquim-Alonga, S. A., Madrid, Spain.

\section{References}

1) Beauville, M. \& P. Raynand: Nouvelle technique de confection d'une poche gastrique isoles chez le lapin. C. R. Acad. Sci. (Paris) 267: 1153 1156, 1968

2) Gibaldi, M. \& D. Perrier: Pharmacokinetics. p. 11, Marcel Dekker inc., New York, 1975

3) Gibaldi, M. \& D. Perrier: Pharmacokinetics. p. 146, Marcel Dekker Inc., New York, 1975

4) Harada, Y.; S. Matsubara, M. Kakimoto, T. Noto, T. Nehashi, T. Kimura, S. Suzuki, H. Ogawa \& K. Koyama: Ceftezole, a new cephalosporin $\mathrm{C}$ derivative. II. Distribution and excretion in parenteral administration. J. Antibiotics 29: 1071 1082, 1976

5) Loo, J. C. K. \& S. Riegelman: New method for calculating the intrinsic absorption rate of drugs. J. Pharm. Sci. 57: 918 928, 1968

6) Kavanagh, F.: Analytical Microbiology. Vol. II. Academic Press Inc., New York-London, 1972

7) Riegelman, S.; J. Loo \& M. Rowland: Concept of a volume of distribution and possible errors in evaluation of this parameter. J. Pharm. Sci. 57: 128 133, 1968

8) Saunders, L. \& T. Natunen: A statistical approach to pharmacokinetics calculations. J. Pharm. Pharmac. 24 (suppl.): 94 99, 1972

9) Schwartz, D.: Methodes statistiques à l'usage des medecins et des biologistes. p. 228, Ed. Plammarion, Paris, 1963

10) VILA, J. L. \& A. A. Dominguez-GIL: Relaciones entre los parámetros farmacocinéticos y farmacodinámicos en la Tolbutamida. I. Boll. Chim. Farm. 117: 47 53, 1978

11) Vila, J. L. \& A. A. Dominguez-Gil: Relaciones entre los parámetros farmacocinéticos y farmacodinámicos en la Tolbutamida. II. Boll. Chim. Farm. 117: 240 245, 1978

12) Wagner, J. G.: Biopharmaceutics and Relevant Pharmacokinetics. p. 295, Drug Intelligence Publications, Hamilton III, Illinois, 1971

13) Wagner, J. G.: Fundamentals of Clinical Pharmacokinetics. p. 83, Drug Intelligence Publications, Hamilton I, Illinois, 1975

14) Wagner, J. G.: Fundamentals of Clinical Pharmacokinetics. p. 286, Drug Intelligence Publications, Hamilton I, Illinois, 1975

15) YAMAZAKI, T. \& K. TSUCHIYA: 3-Deacetoxy-7-( $\alpha$-amino-1-cyclohexenylacetamido) cephalosporanic acid (SCE-100), new semisynthetic cephalosporin. III. Comparative studies on absorption, distribution and excretion of SCE-100 and cephalexin (CEX) in laboratory animals. J. Antibiotics 29: 571 578, 1976 